\title{
RNA sequencing provides evidence for functional variability between naturally co-existing Alteromonas macleodii lineages
}

\author{
Nikole E Kimes ${ }^{1,2^{*} \dagger}$, Mario López-Pérez ${ }^{1 \dagger}$, Eva Ausó ${ }^{1}$, Rohit Ghai ${ }^{1}$ and Francisco Rodriguez-Valera ${ }^{1}$
}

\begin{abstract}
Background: Alteromonas macleodii is a ubiquitous gammaproteobacterium shown to play a biogeochemical role in marine environments. Two A. macleodii strains (AltDE and AltDE1) isolated from the same sample (i.e., the same place at the same time) show considerable genomic differences. In this study, we investigate the transcriptional response of these two strains to varying growth conditions in order to investigate differences in their ability to adapt to varying environmental parameters.
\end{abstract}

Results: RNA sequencing revealed transcriptional changes between all growth conditions examined (e.g., temperature and medium) as well as differences between the two A. macleodii strains within a given condition. The main inter-strain differences were more marked in the adaptation to grow on minimal medium with glucose and, even more so, under starvation. These differences suggested that AltDE1 may have an advantage over AltDE when glucose is the major carbon source, and co-culture experiments confirmed this advantage. Additional differences were observed between the two strains in the expression of ncRNAs and phage-related genes, as well as motility.

Conclusions: This study shows that the genomic diversity observed in closely related strains of A. macleodii from a single environment result in different transcriptional responses to changing environmental parameters. This data provides additional support for the idea that greater diversity at the strain level of a microbial community could enhance the community's ability to adapt to environmental shifts.

Keywords: Alteromonas macleodii, Genomic diversity, RNA-seq, Transcriptomics, Genomic islands, CRISPR

\section{Background}

Alteromonas macleodii, a marine gammaproteobacterium, is distributed globally and especially abundant in the temperate and tropical latitudes [1-4]. A quintessential marine $r$-strategist, it plays an important biogeochemical role in marine waters, and recent metatranscriptomic studies have highlighted its important role in marine dissolved organic carbon and nitrogen recycling $[5,6]$. Isolations and genome sequencing of a number of $A$. macleodii strains from different regions of the world have also contributed towards an increasing understanding of this microbe's ecological niche [1,2]. It has been known for years that

\footnotetext{
*Correspondence: nikolekimes@gmail.com

${ }^{\dagger}$ Equal contributors

'Evolutionary Genomics Group, División de Microbiología, Universidad Miguel Hernández, Apartado 18, San Juan 03550, Alicante, Spain

${ }^{2}$ Current affiliation: Department of Medicine, University of California San Francisco, 513 Parnassus Ave, San Francisco, CA 94143, USA
}

Alteromonas cells are associated to the particulate fraction [7] and capable of nutrient cycling [8]. More recently, genome sequencing provided evidence for further specialization within $A$. macleodii based on the particulate matter associated with each strain, suggesting that most surface isolates are associated to small, slow sinking particles, while deeper isolates live on larger faster sinking aggregates [9]. The two strains studied here, AltDE and AltDE1, were isolated from a single deep $(1000 \mathrm{~m})$ seawater sample from the South Adriatic (Mediterranean Sea) and both belong to the "large particle" or "deep" ecotype or subspecies [3]. These two strains have a high average nucleotide identity (ANI, 98.51\%) when comparing their core genomes (3631 shared genes, $\sim 80 \%$ of genome) [3]. However, these concurrent isolates still differ from each other in 9 flexible genomic islands, which are located in the same genomic context yet contain different genes plus a number of small 
insertions and deletions, some involving complete gene clusters [3]. The collective pool of genes detected among the strains in a single species is referred to as the pan-genome $[10,11]$ and has now been described in many microorganisms [10-15]. However, most of these studies examine the gene pool of strains that are not found together in the same natural population. This leads researchers to assign their differences to specific adaptations to their habitat. In the case of AltDE and AltDE1, isolated from the same sample, the considerable genomic variation observed has been interpreted as contributing to adaptation to even more specialized microniche partitioning [3]. In fact, the coexistence of such closely related, yet distinct, $A$. macleodii strains within a single sample brings up a number of questions. For example, do the flexible genomic regions represent functional differences between the strains under ecologically relevant conditions? It has been speculated that the gene diversity presented by pan-genomes provides a broader range of ecological capabilities and adaptability within a species [16], However, more evidence to support such assertions is required. These naturally coexisting strains of $A$. macleodii provide an excellent opportunity to examine the responses of each strain, including the transcriptional expression of both the core and flexible genome, under different conditions in an attempt to identify the nature of adaptive advantages conferred by their genomic differences.

We hypothesized that the two strains would exhibit distinct transcriptional responses to a variety of environmental conditions. Thus providing evidence for the differences expected from the variable flexible gene pools. We also wanted to examine whether or not their genomic differences affect their competitiveness in cocultures under ecologically relevant conditions, and whether their transcriptional profiles provide clues to the observed responses. To investigate these hypotheses, we performed RNA-sequencing on AltDE and AltDE1 grown in four different conditions, providing a total of eight transcriptomes. The four conditions included growth in rich medium at two different temperatures $\left(13^{\circ} \mathrm{C}\right.$ and $\left.25^{\circ} \mathrm{C}\right)$ and minimal medium at $25^{\circ} \mathrm{C}$ with glucose as the sole carbon source and subsequently two days after removal of the carbon source (i.e., starvation). Furthermore, we examined the population dynamics of the two strains during co-culture to assess the effect of growth conditions on the population structure. Our results show that AltDE and AltDE1 exhibit specific adaptations, giving each strain an advantage under different ecological conditions in large part due to expression of their flexible genomes. This supports the theory that genetic diversity within a population provides a broader arsenal for adaptation within a given community.

\section{Results and discussion}

\section{Overview of RNA-seq results}

In this study we used different growth conditions to explore the differences between two distinct, yet closely related, A. macleodii strains isolated from the same environmental sample: AltDE and AltDE1. The conditions included two temperatures $\left(13\right.$ and $\left.25^{\circ} \mathrm{C}\right)$, which represent normal temperature extremes in the Mediterranean (winter and summer respectively), and two growth media, a commonly used laboratory medium (marine broth or nutrient-rich medium, RM), used at both temperatures and a minimal medium with glucose (MMG), only at $25^{\circ} \mathrm{C}$. Another condition assayed was starvation (STR), in which cells grown in MMG at $25^{\circ} \mathrm{C}$ were deprived of any carbon source for 48 hours. Using these growth conditions ( $\mathrm{N}=4$ for each strain), we sequenced the cDNA of AltDE and AltDE1, resulting in over 50 million paired end reads that we were able to map to the AltDE and AltDE1 genomes accordingly (Table 1).

We have sequenced total RNA (both rRNA and mRNA) from A. macleodii transcriptomes to reduce bias introduced by mRNA enrichment [17]. The depth of sequencing that can now be achieved from Illumina sequencing is sufficient to provide adequate coverage of the mRNA without rRNA depletion [18]. As expected, the vast majority of reads (ranging from 93.1 to $99.8 \%$ ) in all eight transcriptomes mapped to the rRNA operons (Table 1). For the growing cells, the two nutrient rich conditions revealed lower percentages of rRNA transcripts (93.1 94.3\%) than the minimal medium (97.5 - 98.5\%). There might be a larger ribosome concentration in the minimal medium grown cells or some specific genes are much more expressed in the rich medium (see below). The percentage of CDS expressed was similar in both growth media at $25^{\circ} \mathrm{C}$ (ca. 90\%). However, it was significantly smaller at $13^{\circ} \mathrm{C}$ (76.9 and $82.7 \%$ in DE and DE1 respectively), which might be a consequence of the lower growth rate at this temperature. Even after removal of the rRNA reads, we obtained sensible genome coverage ranging from $4.1 \mathrm{X}$ to $14.8 \mathrm{X}$. In the starvation (STR) experiments, the two strains differed markedly with much larger amounts of rRNA reads in the case of AltDE1. Where the AltDE genome remained largely active at the transcriptional level under starvation, AltDE1 appeared to have shut down transcription through most of its genome. It has been reported that under certain stress conditions, such as starvation, bacteria respond to adverse conditions reducing translational activity, leading to slow cell growth [19].

We identified differentially expressed genes between the conditions analyzed using a cut-off criteria of $\geq 2$ fold $\log$ increases for up-regulated genes (Figure 1). A general up-regulation of genes across the AltDE and AltDE1 genomes at $25^{\circ} \mathrm{C}$ (over $75 \%$ of the total differentially 
Table 1 RNA sequencing results

\begin{tabular}{|c|c|c|c|c|c|c|c|c|}
\hline \multirow{2}{*}{$\begin{array}{c}\text { Strain } \\
\text { Growth Conditions }\end{array}$} & \multicolumn{4}{|c|}{ AltDE } & \multicolumn{4}{|c|}{ AltDE1 } \\
\hline & $\mathrm{RM}^{\mathrm{a}}-13^{\circ} \mathrm{C}$ & $\mathrm{RM}^{\mathrm{a}}-25^{\circ} \mathrm{C}$ & $\mathrm{MMG}^{\mathrm{b}}-25^{\circ} \mathrm{C}$ & $S T R^{\mathrm{C}}-25^{\circ} \mathrm{C}$ & $\mathrm{RM}^{\mathrm{a}}-13^{\circ} \mathrm{C}$ & $\mathrm{RM}^{\mathrm{a}}-25^{\circ} \mathrm{C}$ & $\mathrm{MMG}^{\mathrm{b}}-25^{\circ} \mathrm{C}$ & $\mathrm{STR}^{\mathrm{C}}-25^{\circ} \mathrm{C}$ \\
\hline Total number of reads & $3,444,176$ & $11,503,336$ & $8,986,648$ & $2,995,620$ & $6,230,679$ & $7,840,241$ & $13,514,524$ & $14,695,977$ \\
\hline Reads mapped to ribosomal operons & $3,206,468$ & $10,852,030$ & $8,764,784$ & $2,940,326$ & $5,812,308$ & $7,342,658$ & $13,314,002$ & $14,668,090$ \\
\hline $\begin{array}{c}\text { Percentage of reads mapped to ribosomal } \\
\text { operons }\end{array}$ & 93.1 & 94.3 & 97.5 & 98.2 & 93.2 & 93.7 & 98.5 & 99.8 \\
\hline Chromosome length (nt) & \multicolumn{4}{|c|}{$4,480,937$} & \multicolumn{4}{|c|}{$4,643,844$} \\
\hline Average coverage per nucleotide ${ }^{d}$ & $8.7 X$ & $14.8 \mathrm{X}$ & $5.0 \mathrm{X}$ & $1.2 X$ & $8.9 X$ & $10.5 x$ & $4.1 X$ & $0.6 \mathrm{X}$ \\
\hline Percentage of CDS expressed & 76.9 & 90.3 & 86.5 & 86.2 & 82.7 & 88.8 & 87.6 & 43.7 \\
\hline Reads mapped in the chromosome & 387,708 & 661,306 & 221,864 & 55,294 & 412,700 & 487,487 & 191,820 & 27,243 \\
\hline Reads mapped to CDS & 258,240 & 454,504 & 160,098 & 40,566 & 275,125 & 325,206 & 139,930 & 21,824 \\
\hline Percentage of reads mapped to $I R$ & 33.4 & 30.2 & 27.8 & 26.6 & 33.3 & 33.3 & 27.1 & 19.8 \\
\hline $\begin{array}{c}\text { Percentage of reads mapped to ribosomal } \\
\text { proteins }\end{array}$ & 21 & 22.9 & 11.2 & 6 & 20.9 & 20.1 & 4 & 1.2 \\
\hline Plasmid length (nt) & - & - & - & - & \multicolumn{4}{|c|}{303,282} \\
\hline Average coverage per nucleotide & - & - & - & - & $1.9 \mathrm{X}$ & $3.3 x$ & $2.9 \mathrm{X}$ & $0.2 X$ \\
\hline Reads mapped to plasmid & - & - & - & - & 5,671 & 10,096 & 8,702 & 644 \\
\hline
\end{tabular}

CDS, coding DNA sequence; IR, intergenic region.

anutrient rich marin medium.

${ }^{\mathrm{b}}$ minimal medium with $1 \%$ glucose.

cminimal medium with $1 \%$ glucose followed by two days of minimal medium without glucose.

${ }^{d}$ number of mapped reads X 100 /number of nucleotides in the chromosome.

epercentage of CDS.

expressed) compared to $13^{\circ}$ was detected (Figure 1). Although AltDE and AltDE1 exhibited similar transcriptional fingerprints for the most part at $25^{\circ} \mathrm{C}$, there was a large peak of up-regulation observed that was unique to AltDE (Figure 1). Examination of these genes revealed the up-regulation of a flexible region (fGI-3) that consists entirely of an integron [20] in both strains. Despite the fact that the integron integrases were $99.1 \%$ identical in both strains, the gene cassettes inserted in the downstream region were totally different. Cassettes are promoterless and conditioned to the Integron $P c$ promoter that is embedded in the integrase [21]. However, in the case of the A. macleodii strains studied here each cassette displayed independent regulation. For example, all the toxin-antitoxin systems (suggested to be involved in the stabilizing of the integron) were up-regulated in STR, while the nearest gene cassette to the integron integrase in AltDE1 showed no expression under any condition.

Broad scale comparison also shows that the two strains differ in their response to the growth medium, with AltDE1 overexpressing many more genes in MMG than AltDE (Figure 1). Also in AltDE1, we observed six unique peaks of up-regulation. Three of them in RM correspond to regions encoding ribosomal proteins. In contrast, two peaks in the MMG were associated with pilus and antioxidant production, while the third peak corresponded to a genomic island (GI-7) encoding a different lambda-like phage in each strain. Interestingly, in AltDE1 GI-7 is expressed in both MMG and STR, while the AltDE phage- like region (GI-3) is only expressed under the most severe starving condition (Figure 2). In this comparison, for example we identified a considerable change in relative expression of a number of genes which are involved in nitrogen metabolism (Additional file 1: Table S1). Among these, a gene coding for a PII-like signal transduction protein (GlnK) that regulates the expression of $g \ln A-n \operatorname{tr} B C$ operon [22] and an ammonium transporter (amtB) during nitrogen starvation showed the greatest expression in MMG in comparison to RM (11.02 and 13.97 fold change in DE and DE1 respectively) in both strains. Likewise, the $g \ln A$ gene, which encodes glutamine synthetase that is the central enzyme for nitrogen assimilation from ammonia into glutamine and the nitrate $\mathrm{ABC}$ transporter ( $\mathrm{ntrC}$ ), were also up-regulated. The same pattern was conserved for most of the genes involved in ammonium uptake and assimilation as well as genes coding for nitrogen assimilatory enzymes, e.g., nirBD. Although all of these nitrogen related genes were induced in both strains in MMG, most of these genes showed stronger induction levels for AltDE1 than AltDE (Additional file 1: Table S1).

The variability between AltDE and AltDE1 appeared to be greater in the differentially expressed genes between MMG and STR compared to the variability observed between the other conditions (Figure 1). Despite the low proportion of genes that were expressed in AltDE1 STR, $53 \%$ were differentially expressed compared to MMG. The genes of the Integrative and Conjugative Element (ICE) which were expressed at higher levels under STR, 


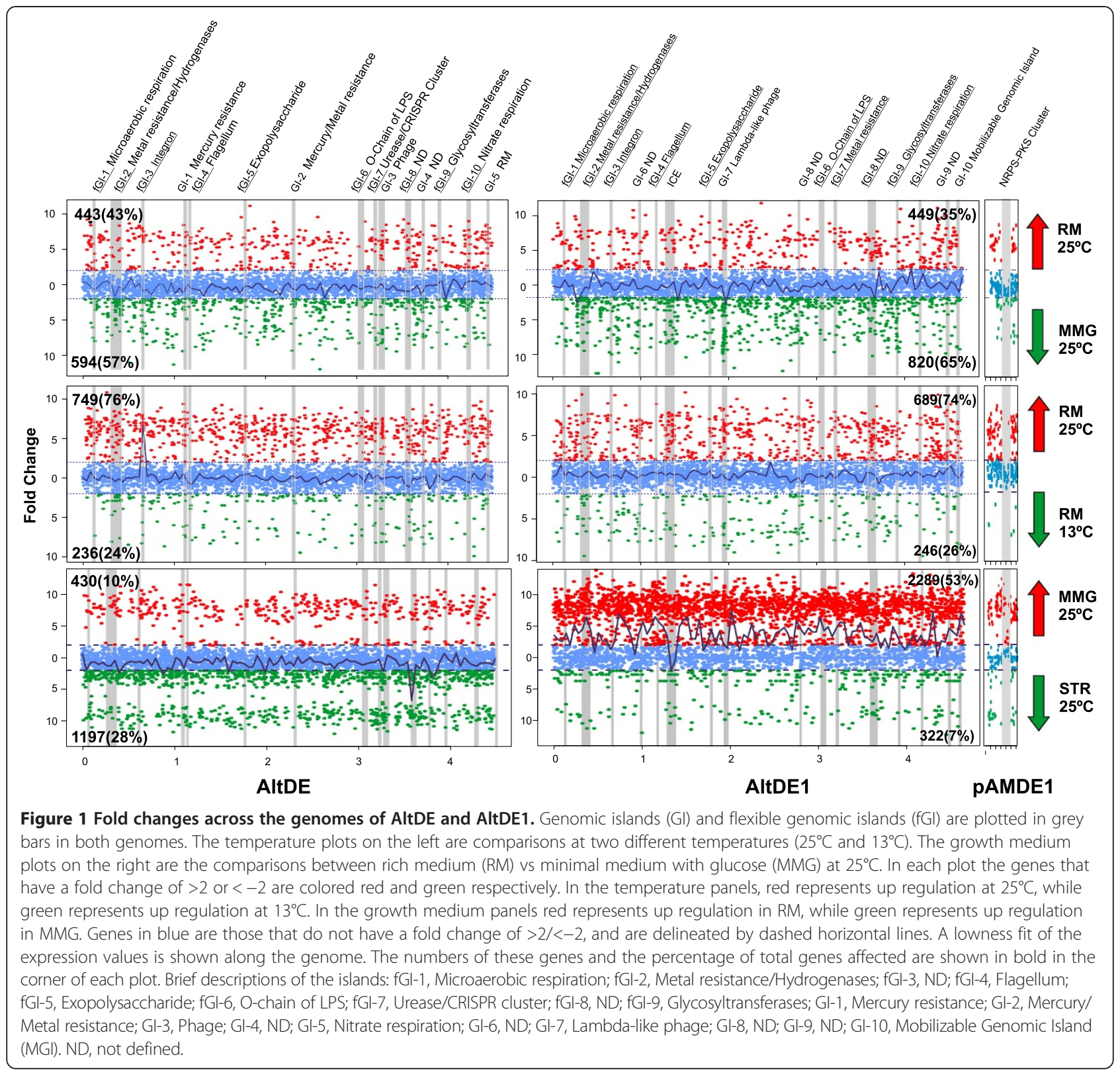

represented the only significant difference between these two conditions in AltDE1. AltDE exhibited the reverse situation suggesting that this strain may have an advantage under circumstances of nutrient deprivation. We also identified a marked peak at STR in AltDE corresponding to the fGI-8, but no function could be inferred for this GI (Figure 1). Due to the high similarity between the two strains (3631 core genes), these results highlight the relative importance of the flexible genome in the different adaptive responses observed of the species especially during STR conditions.

AltDE1 also carries a 300-kb conjugative plasmid (pAMDE1) previously described by Gonzaga et al. [3].
The expression profile of the hybrid non-ribosomal peptide synthetase-polyketide synthase (NRPS-PKS) gene cluster, which was predicted to produce a bleomycin-like compound and contains a bleomycin-resistance gene [23], revealed increased expression in MMG compared to RM or STR (Additional file 2: Figure S1). This suggests that glucose is an inductor for the production of this compound.

We also performed hierarchical clustering (Figure 3) using the expression of orthologous genes in AltDE and AltDE1 (i.e., the core genome) and revealed that the main driver of differential gene expression was the growth medium followed by temperature and finally the strain. This indicates that both strains' core genomes (3631 


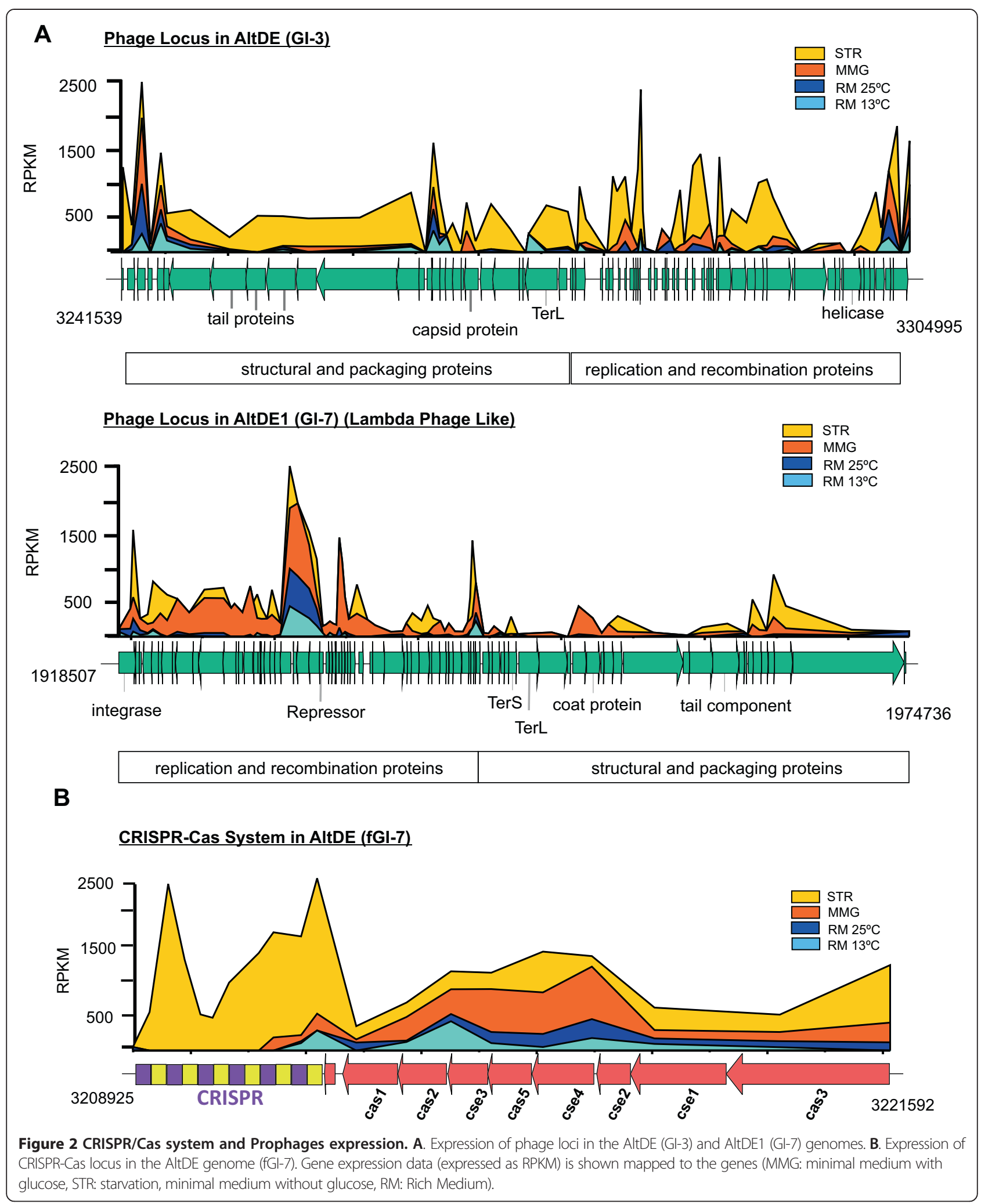

genes) react similarly to the variations in growth conditions. Furthermore, the fact that the core genome contributes to the majority (67-79\%) of differentially expressed genes in each condition (Table 2) clearly demonstrates its role in the observed changes. These core genes include regulatory elements (e.g. ncRNAs 


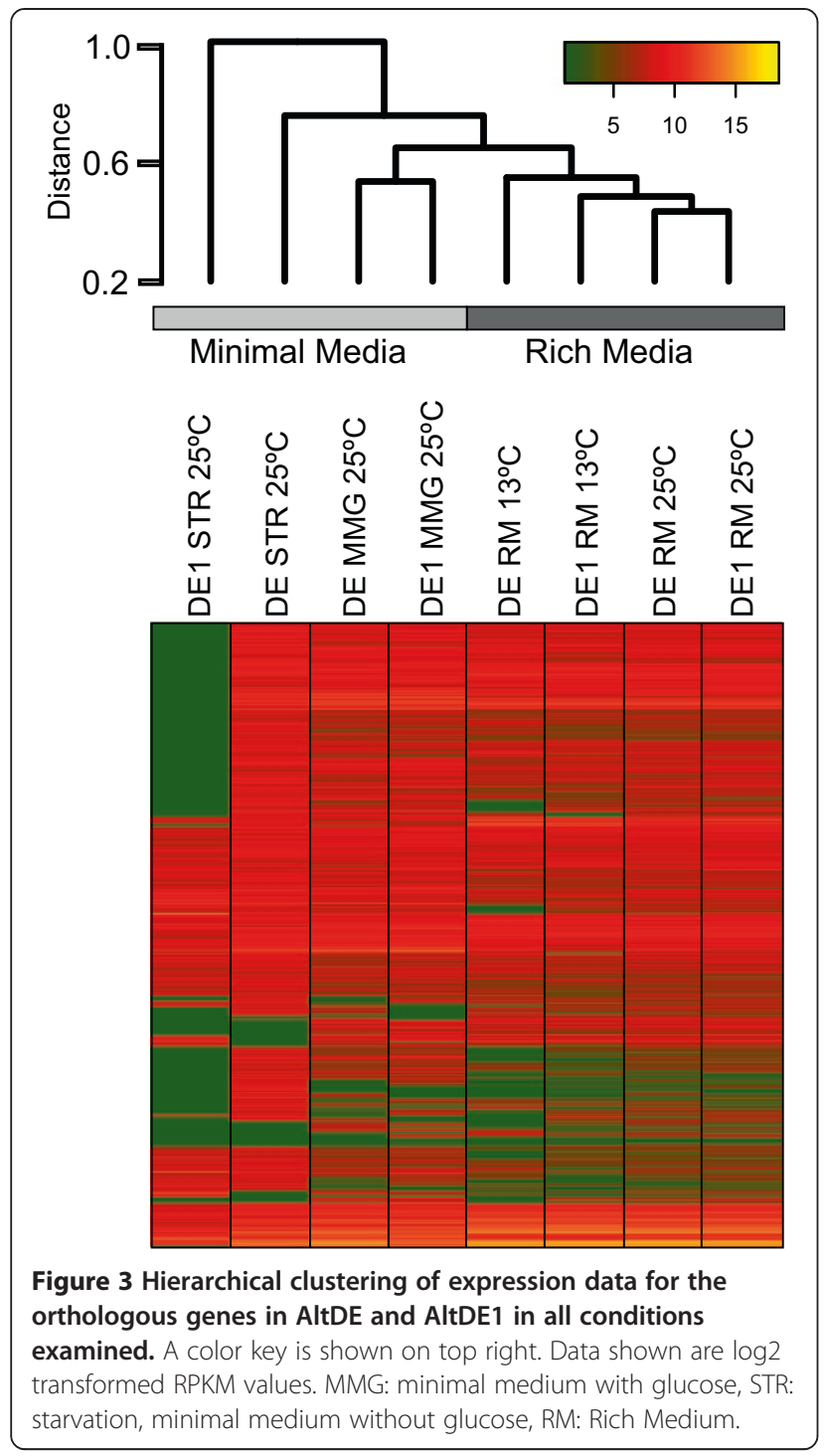

and transcription factors) and nutrient cycling genes (e.g. carbon and nitrogen cycling genes).

The gene content of the flexible genome, in contrast to the core genome, differs widely between AltDE and AltDE1, representing 17 and $24 \%$ of their respective genomes, mostly due to the presence of the large plasmid (pAMDE1) in AltDE1. In the transcriptomes, the percentage of the flexible genes in each genome that were differentially expressed was slightly higher than that observed among the shared genes (Table 2). The differential expression within a strain was also very marked (quantitatively) for some flexible genomic regions. For example, the AltDE Integron (fGI-3) between 13 and $25^{\circ} \mathrm{C}$ or fGI8 between MMG and STR (Figure 1). Using the total genes that are differentially expressed in each condition as a reference, the differentially expressed flexible genes account for $21-33 \%$ of that total (Table 2). This is notable since a recent study using the RNA sequencing of Clostridium difficile reported a much lower effect $(<5 \%)$ on the flexible genome when examining differences between growth conditions [24]. Our data clearly show that in addition to a significant contribution from core genome components flexible genes play an important role in the observed changes between conditions and strains.

The transcriptional data of AltDE and AltDE1 also show that of all of the hypothetical proteins in these genomes ( 30\% in each), the vast majority, 93\% (1136 of 1220) in AltDE and 90\% (1077 of 1192) in AltDE1, are expressed. In fact, hypothetical genes account for $\sim 50 \%$ of the most highly altered genes between two conditions (Additional file 1: Table S2). In AltDE, for example, 56 of the 100 most highly up- or down-regulated genes between 13 and $25^{\circ} \mathrm{C}$ were annotated as hypothetical, similar to that of AltDE1 (54 of 100). This data highlights the need for further investigation of hypothetical genes, while it also provides some insight into which ones likely play an important role in adapting to variable growth conditions.

\section{Effects of starvation}

Despite the low genome coverage and the low percentage of genes expressed in AltDE1, the difference between AltDE and AltDE1 in the STR condition is notable. The number of reads obtained from the STR transcriptomes was comparable, if not higher, than the other conditions (Table 1), suggesting that additional sequencing would not have necessarily provided significantly higher genome coverage. Despite the lower coverage in these conditions, we detected at least $86 \%$ expressed genes in AltDE and $43 \%$ in AltDE1 (Table 1). This leads us to speculate that the lower AltDE1 gene expression observed in STR could be the result of a more rapid physiological adaptation rather than a lack of sequencing depth.

Notably, 56\% of the total AltDE1 transcriptomic reads under STR mapped to two ncRNAs, tmRNA and RNaseP (discussed below). This contrasts with AltDE, in which only $21 \%$ of reads mapped to the same ncRNA. Along with these two ncRNAs, the $c s b D$ gene was the most highly expressed in AltDE1 during STR (Additional file 1: Table S3). In Bacillus subtilis the expression of this gene, mediated by sigma-B, was induced in response to phosphate starvation, although its exact function remains unknown [25]. Other highly expressed genes encoded two ribosome-associated proteins, ribosome modulation factor (RMF) and ribosome release factor (RRF). In Escherichia coli RMF was shown to have an influence on the protection against acid stress during stationary phase [26] and heat stress [27] acting as a protective factor of ribosomes during times of slow growth. Moreover, RRF is involved in the dissociation of ribosomes from mRNA and is essential 
Table 2 Number of genes differentially expressed in AltDE and AltDE1

\begin{tabular}{|c|c|c|c|c|c|c|}
\hline Strain & & AltDE & & & AltDE1 & \\
\hline Total genes in the genome & & 4389 & & & 4748 & \\
\hline Total core genes in the genome $(\%)^{a}$ & & $3631(83)$ & & & $3631(76)$ & \\
\hline Total flexible genes in the genome $(\%)^{a}$ & & $758(17)$ & & & $1117(24)$ & \\
\hline Comparison & $\begin{array}{c}\text { Temperature } \\
\left(13-25^{\circ} \mathrm{C}\right)\end{array}$ & $\begin{array}{c}\text { Media } \\
\text { (RM-MMG) }\end{array}$ & $\begin{array}{c}\text { Media } \\
\text { (MMG-STR) }\end{array}$ & $\begin{array}{c}\text { Temperature } \\
\left(13-25^{\circ} \mathrm{C}\right)\end{array}$ & $\begin{array}{c}\text { Media } \\
\text { (RM-MMG) }\end{array}$ & $\begin{array}{c}\text { Media } \\
\text { (MMG-STR) }\end{array}$ \\
\hline Total genes differentially expressed $(\%)^{a}$ & $985(22)$ & $1037(24)$ & $1627(37)$ & $1026(22)$ & $1362(29)$ & $2771(58)$ \\
\hline Total core genes differentially expressed $(\%)^{\mathbf{b}}$ & $763(21)$ & $809(22)$ & $1286(35)$ & $684(19)$ & $978(27)$ & $2143(59)$ \\
\hline $\begin{array}{l}\text { Contribution of core genes to total genes } \\
\text { differentially expressed }\end{array}$ & $77 \%$ & $78 \%$ & $79 \%$ & $67 \%$ & $72 \%$ & $77 \%$ \\
\hline Total flexible genes differentially expressed $(\%)^{c}$ & $222(29)$ & $230(30)$ & $342(45)$ & $342(30)$ & $384(34)$ & $629(56)$ \\
\hline $\begin{array}{l}\text { Contribution of flexible genes to total genes } \\
\text { differentially expressed }\end{array}$ & $23 \%$ & $22 \%$ & $21 \%$ & $33 \%$ & $28 \%$ & $23 \%$ \\
\hline
\end{tabular}

RM, nutrient rich marine medium.

MMG, minimal medium with $1 \%$ glucose.

STR, starvation.

Genes with a $\log 2$ fold change of more than 2 are considered differentially expressed.

a percentage $=$ value/total number of genes in the genome.

${ }^{b}$ percentage $=$ value/total core genes .

$c_{\text {percentage }}=$ value $/$ total flexible genes .

for bacterial growth [28]. Although more evidence is necessary, these data indicate that AltDE1 may undergo a significant transcriptional shift, which alters the ribosomal processes in a way that allows long-term survival during STR and differs from AltDE.

\section{CRISPR/Cas system and Prophages expression}

Transcriptomic data also provides an important tool to assess whether prophages participate in the physiology of these two representatives of $A$. macleodii. Both AltDE and AltDE1 harbor a prophage inserted in their genomes (GI-3 in AltDE and GI-7 in AltDE1), and both appear to encode recognizable structural, replication and recombination proteins (e.g. capsid and tail proteins, helicases, terminases, integrase etc.) [1,3] Neither of these shows any kind of similarity to known Alteromonas phage isolates [29], and it is not known whether or not either of these can enter lytic cycles and produce viable phages. However, in both strains several genes are expressed in these regions (Figure 2), suggesting some activity. In AltDE, the locus showed higher expressions levels in several genes in STR, akin to the CRISPR-locus expression, while only a few genes were expressed in the other conditions. In total, over 37 of the 71 genes were found to increase in expression by at least 2-fold in STR compared to the levels seen in MMG. This data suggest that under this condition the AltDE prophage is apparently induced and could trigger the entry into lytic cycle. In AltDE1, 58 and 47 of the 82 genes of the lambda-like prophage were up-regulated in MMG in relation to RM and STR respectively. These data demonstrate that under adverse conditions, such as starvation, prophages are not passive elements of the bacterial genome but may be active participants in cell physiology. In both prophages there were some genes expressed in all the conditions that change their expression levels in response to environmental perturbations. Other examples of such genes have been reported as cargo genes, which are non-essential for phage proliferation and instead confer adaptive advantages against environmental stress [30] and are potentially involved in virulence [31].

Previously, we reported the presence in AltDE genome of a complete set of CRISPR and CRISPR-associated sequence (Cas) proteins completely absent in AltDE1 [8]. The CRISPR locus has been shown to protect bacteria against foreign nucleic acids such as plasmids and viruses [32]. One of the most significant responses to STR was the increased expression of CRISPR in the AltDE genome (Figure 2) while in the other conditions only minimal expression was detected in $\mathrm{RM}$ at $25^{\circ} \mathrm{C}$. Interestingly, the entire repeat array was expressed in the STR condition while only a small region was detectably expressed in other conditions. These data suggest that the CRISPR/Cas system may be involved in other cellular functions as has been demonstrated previously for biofilm formation [33] and DNA repair [34].

\section{Motility}

AltDE and AltDE1 genomes differed with regard to their flagellar operons and that AltDE1 displayed significantly higher motility than AltDE when grown in RM at $25^{\circ} \mathrm{C}$ [3]. Examination of the gene expression levels of numerous motility related genes revealed that a cluster of genes within the flagellar operon, including the regulatory genes flaKLM and the structural genes fliEFGHIJK, showed different expression levels in AltDE1 (compared to AltDE) in 
both $\mathrm{RM}$ at $25^{\circ} \mathrm{C}$ and the MMG (Figure 4). However, at $13^{\circ} \mathrm{C}$, this cluster was not up-regulated. Although all the genes of this cluster showed higher expression in AltDE1 only flaK, flaL flaM, fliJ and fliK demonstrate up-regulation (fold change $>2$ in AltDE1) during growth in $\mathrm{MMG}$ and $f l i K$ in $\mathrm{RM}$ at $25^{\circ} \mathrm{C}$. If this cluster of genes is responsible for the difference in motility between the two strains, we would expect differences at $25^{\circ} \mathrm{C}$ ( $\mathrm{RM}$ and $\mathrm{MMG}$ ) but not in $\mathrm{RM}$ at $13^{\circ} \mathrm{C}$. This was confirmed using motility assays where AltDE1 exhibited significantly greater motility in both $\mathrm{RM}$ at $25^{\circ} \mathrm{C}(\mathrm{p}<$ 0.001, paired $T$-test, 2-tailed) and MMG $(\mathrm{p}<0.01$, paired $T$-test, 2 -tailed), while no significant difference was found in $\mathrm{RM}$ at $13^{\circ} \mathrm{C}$, even though both strains appeared motile, though less than at $25^{\circ} \mathrm{C}$ (Additional file 1: Table S4). Despite exhibiting an up-regulation in their expression, nucleotide similarity between both genomes was nearly identical in the $f l i K$ genes $(99.6 \%)$; therefore, such variability observed could be due to the regulatory genes
flaK and flaL, which sequence were remarkably variable (80 and $84.9 \%$, respectively). The transcriptomic and motility data provide additional support for our previous suggestion that the FlaKLM regulatory system plays a role in the variable motility response of AltDE and AltDE1 to different environmental conditions [3].

\section{Expression of Non-coding RNA}

In addition to examining the differences in gene expression between AltDE and AltDE1, our RNA-seq data allowed us to map the expression of putative noncoding RNA genes (ncRNAs), previously unannotated in $A$. macleodii. ncRNA are small functional RNA that are not translated into a protein, but rather play important roles as post-transcriptional regulators involved in diverse bacterial processes [35]. After excluding putative tRNAs, sixteen transcripts not overlapping to any previously annotated coding region were identified in the AltDE and AltDE1 chromosomes, while none were identified in the

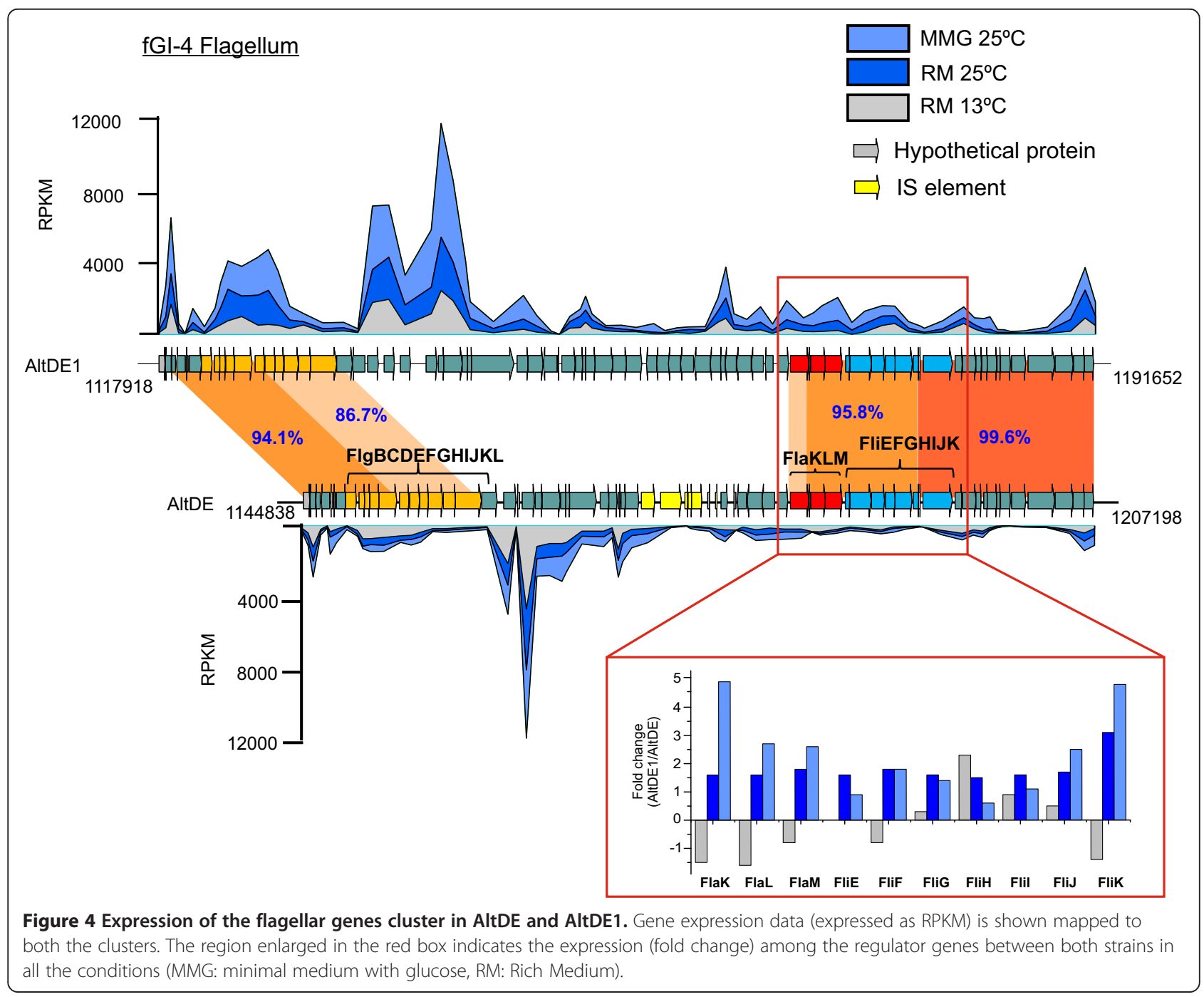


plasmid pAMDE1. Fourteen of these, ranging in size from 70 to $359 \mathrm{nt}$, were identified as putative ncRNA genes using Rfam 10.1 [36] and Bacterial Small Regulatory RNA (BSRD) [37] databases, and two remain unidentified (Table 3). Twelve ncRNAs were found in both strains, and four were found specifically in AltDE1.

Five highly conserved bacterial ncRNAs (Alpha RBS, RNase P, Small SRP, tmRNA and 6S RNA) were found in both strains. Notably, genes coding for tmRNA and RNAse $\mathrm{P}$ were among the most highly expressed in all of the transcriptomes, with the greatest levels associated with oligotrophic conditions. In AltDE1, for example, these two ncRNA were the two most highly expressed genes when grown in minimal medium and exhibited increased tmRNA (4X) and RNAse P (2X) levels in MMG compared to their expression in RM at $25^{\circ} \mathrm{C}$ (Additional file 1: Table S3). RNAseP is a ribozyme that was initially shown to catalyze the removal of the $5^{\prime}$ end of pre-tRNAs to produce the mature transfer RNAs (tRNAs) [38]. However, recent discoveries have revealed that is also involved in transcriptional machinery and in the maturation of other RNA substrates, such as mRNAs, precursor tmRNA and riboswitches [39]. tmRNA is a molecule with properties of both a tRNA and an mRNA that is required to release stalled ribosomes and target nascent polypeptides for degradation.
Evidence of increased tmRNA levels in cells under different types of stressful conditions $[40,41]$, including starvation $[42,43]$ suggests that the cell might increase the tmRNA levels to deal with incompletely-translated and stalled proteins resulting from stress. Ecologically, this is relevant because increased levels of tmRNA observed during starvation likely provide a needed source of amino acids for the synthesis of new proteins from the degradation or recycling of the aberrant proteins [44]. Furthermore, A. macleodii is an $r$-strategist (i.e., bloomer) that takes advantage of sporadic inputs of high nutrients in the normally depleted oligotrophic sea, requiring the ability to sense and rapidly respond to nutrient availability. For this purpose, ncRNAs are the perfect regulators due to their immediate availability since they do not require the translation into protein and because of the wide range of cellular responses they can modulate.

We have also found several riboswitches, small RNA that can regulate gene expression by directly binding a small molecule ligand [45]. One of these highly conserved riboswitches was found in the $5^{\prime}$-untranslated region of the thiamine pyrophosphate (TPP) operon and is known to be involved in TPP regulation through the prevention of TPP transcription [46]. RNA leader sequences are another type of riboswitches classified as cis-acting ncRNAs. Within the AltDE and AltDE1

Table 3 Expression of ncRNAs in AltDE and AltDE1

\begin{tabular}{|c|c|c|c|c|c|c|c|c|c|c|c|}
\hline \multirow{2}{*}{$\begin{array}{l}\text { Strain } \\
\text { ncRNA }\end{array}$} & \multirow[b]{2}{*}{ Start* } & \multirow[b]{2}{*}{ End* } & \multirow[b]{2}{*}{$\begin{array}{l}\text { Length } \\
\text { (bp) }\end{array}$} & \multicolumn{4}{|c|}{ AltDE1 (RPKM) } & \multicolumn{4}{|c|}{ AltDE (RPKM) } \\
\hline & & & & $\mathrm{RM}-13^{\circ} \mathrm{C}$ & $\mathrm{RM}-25^{\circ} \mathrm{C}$ & MMG-25 $5^{\circ} \mathrm{C}$ & STR- $25^{\circ} \mathrm{C}$ & $\mathrm{RM}-13^{\circ} \mathrm{C}$ & $\mathrm{RM}-25^{\circ} \mathrm{C}$ & $\mathrm{MMG}-25^{\circ} \mathrm{C}$ & STR- $25^{\circ} \mathrm{C}$ \\
\hline TPP riboswitch & 152009 & 152120 & 111 & 87.5 & 35.0 & 289.9 & 912.0 & 100.9 & 0.0 & 356.9 & 461.9 \\
\hline G.ll catalytic intron & 167749 & 167819 & 70 & 91.0 & 0.0 & 114.0 & 0.0 & - & - & - & - \\
\hline Ribonuclease P & 891973 & 892323 & 350 & 39927.4 & 30365.4 & 77672.5 & 925092.0 & 30718.2 & 26092.6 & 98179.9 & 107875.0 \\
\hline AltRNa1 & 1066159 & 1066582 & 424 & 20613.4 & 28361.8 & 143798.5 & 90692.6 & 5133.8 & 5444.4 & 61103.3 & 48553.8 \\
\hline Small SRP & 1239467 & 1239563 & 96 & 67.0 & 80.0 & 502.0 & 0.0 & 63.9 & 116.4 & 97.6 & 0.0 \\
\hline TPP riboswitch & 1258919 & 1259022 & 103 & 31.1 & 0.0 & 234.1 & 0.0 & 123.9 & 138.8 & 58.2 & 235.0 \\
\hline Trp leader & 1634441 & 1634532 & 91 & 35.1 & 42.1 & 0.0 & 0.0 & 0.0 & 0.0 & 0.0 & 0.0 \\
\hline tmRNA & 2126827 & 2127186 & 359 & 13072.1 & 11252.9 & 56769.8 & 775951.9 & 12566.4 & 10450.9 & 53778.6 & 72022.3 \\
\hline His leader & 2929451 & 2929568 & 117 & 109.5 & 0.0 & 68.8 & 0.0 & 6.5 & 47.5 & 39.9 & 80.4 \\
\hline 6S RNA & 3357865 & 3358047 & 182 & 423.6 & 529.1 & 1241.9 & 558.1 & 32.9 & 96.1 & 161.2 & 488.1 \\
\hline Thr leader & 3471219 & 3471330 & 111 & 64.5 & 75.2 & 0.0 & 0.0 & 16.1 & 0.0 & 0.0 & 291.4 \\
\hline yybP-ykoY leader & 3679956 & 3680065 & 109 & 117.5 & 70.4 & 147.6 & 464.2 & - & - & - & - \\
\hline Alpha RBS & 4064601 & 4064678 & 77 & 27744.0 & 30238.6 & 5827.2 & 1964.1 & 21842.2 & 19355.7 & 8201.8 & 6306.7 \\
\hline AltRNa2 & 4312594 & 4312902 & 309 & 292.6 & 1215.7 & 2206.4 & 41812.3 & 949.2 & 1393.1 & 1168.1 & 1047.9 \\
\hline G.ll catalytic intron & 4420296 & 4420366 & 70 & 45.5 & 327.3 & 0.0 & 0.0 & - & - & - & - \\
\hline $\begin{array}{c}\text { G.II catalytic intron D1- } \\
\text { D4 }\end{array}$ & 4421022 & 4421188 & 166 & 425.5 & 394.3 & 291.6 & 0.0 & - & - & - & - \\
\hline
\end{tabular}

*AltDE1 was used as a reference to the location of the ncRNA. Expression levels are reported here as the normalized RPKM values. RM, nutrient rich marine medium; MMG, minimal medium with $1 \%$ glucose; STR, starvation; TPP: thiamine pyrophosphate; SRP: Signal recognition particle; Trp leader: Tryptophan operon leader; tmRNA: Transfer-messenger RNA; His leader: Histidine operon leader; Thr leader: Threonine operon leader; RBS: Ribosome binding site. 
chromosome three additional predicted RNA leader sequences involved in amino acid (histidine, tryptophan and threonine) biosynthesis were identified (Additional file 1: Table S2). A third type of cis-acting ncRNAs, a Yybp-ykoY leader, was found in the AltDE1 genome only, though the specific function of these ncRNAs is unknown. Along with Yybp-ykoY leader, there were another three ncRNA that were only present in AltDE1. These genes belonged to group II intron RNAs, which are both mobile genetic elements that catalyze their own splicing as well as catalytic RNAs [47].

For the two remaining non-coding transcripts (AltRN1 and AltRN2), no homologies were found in any ncRNA databases. BlastN searches against the NCBI nucleotide database showed that AltRN1 and AltRN2 had matches only to several representatives of A. macleodii (AltRN1 > 99\% nucleotide identity to all $A$. macleodii strains belonging to the deep ecotype; AltRN2 > 99\% and 88-87\% identity to deep and surface $A$. macleodii ecotypes, respectively). AltRN1 expression in both strains was comparable to the expression of ribosomal genes, and consistently higher in minimal media. Moreover, AltDE1 expressed this gene at higher levels across conditions (Additional file 1: Table S2). For these reasons, AltRN1 would be a good candidate for further study as a potential new ncRNA.

\section{Differences in population structure during co-culture}

The transcriptional data suggests that AltDE1 may have an increased advantage under circumstances where glucose is abundant. However, from these data alone we cannot discern whether these differences result in any ecological advantage/disadvantages per se. To address this issue, we co-cultured AltDE and AltDE1 in RM and MMG in order to determine whether the transcriptional differences observed resulted in a competitive advantage for AltDE1. We also developed a plating assay utilizing differential antibiotic resistance between the two strains to enumerate the colony-forming units (CFUs) from each. The AltDE1 strain carries a large plasmid containing a hybrid non-ribosomal peptide synthetase-polyketide synthase (NRPS-PKS) genes cluster, which is predicted to produce a bleomycin-like compound and contains a bleomycin-resistance gene [23]. We have shown before that AltDE1 is also resistant to Phleomycin (a bleomycin family compound). As a result we could determine CFUs for both strains utilizing marine agar plates with and without Phleomycin. The plates without antibiotic gave us the total count of both AltDE and AltDE1, while the Phleomycin plates represented only the AltDE1 colonies due to its resistance. AltDE colonies were then calculated by subtracting the AltDE1 CFUs from the total CFUs. The CFU results revealed colonies of both AltDE and AltDE1 when the co-culture was grown in RM (Additional file 2: Figure
S2A). In contrast, the co-cultures grown in the MMG resulted in the presence of AltDE1 colonies only (Additional file 2: Figure S2A). These data show, as suggested by the transcriptomic data, that AltDE1 increases its advantage over AltDE under specific conditions in which glucose is the sole source of carbon and that this advantage is not simply based on a faster growth rate.

We also designed a specific PCR strategy exploiting the divergent $\mathrm{O}$-chain region between the two strains, which allowed us to determine relative population levels of both strains in all of the conditions examined. The strain specific amplification of the O-chain gene, admittedly only semi-quantitative, provided an initial indication that both strains maintained relatively consistent populations in co-culture for up to two weeks in the RM at both temperatures (Additional file 2: Figure S2B). Although this contrasted slightly with the CFU results, the discrepancy is likely due to the fact that the region of the AltDE1 Ochain amplified is larger than that of AltDE causing some variation in optimal amplification. Regardless, the populations shifted dramatically in the minimal medium condition (i.e., glucose as sole carbon source), where only the AltDE1 O-chain was amplified (Additional file 2: Figure $\mathrm{S} 2 \mathrm{C}$ ). This corroborated the CFU findings, in accordance with the transcriptomic analysis, that AltDE1 does indeed have an advantage over AltDE when glucose is the sole carbon source. This could be ecologically significant and explain certain strain-level variation as a function of environmental parameters.

\section{Conclusions}

Two closely-related strains of $A$. macleodii, with an ANI of $98.6 \%$ and isolated from the same Mediterranean seawater sample, have been shown to harbor significant genomic variation $[1,3,48]$. Here we use RNA-seq to provide evidence that these genetic differences result in variable transcriptomic profiles. Most significantly, the differences between AltDE and AltDE1 resulted in different adaptation to growth in minimal medium and particularly under starvation. This study also provides evidence that these transcriptional differences influence the population dynamics of AltDE/AltDE1 co-cultures under specific conditions. The apparent advantage of AltDE1 when glucose is the sole carbon source disappears in the presence of rich media, suggesting that AltDE displays a higher affinity for carbon sources other than glucose and illustrating the complementary capacities previously proposed to characterize natural bacterial populations [49]. This highlights the concept that the ever increasing diversity observed within closely related groups of microorganisms, often in the flexible genomic islands, most likely plays a vital role in the ability of a microbial community as a complex mixture of different clonal lineages to adapt to environmental shifts. 


\section{Methods}

\section{Growth of $A$. macleodii strains}

The two strains of $A$. macleodii used in this study have been fully sequenced and described previously: AltDE [9] and AltDE1 [3]. Both strains were initially grown on marine agar plates $(3.5 \%$ sea salt, $0.5 \%$ peptone, $0.1 \%$ yeast extract, and $1.5 \%$ agar), with inoculum taken from frozen glycerol stocks and examined for purity prior to use. Individual colonies were grown in the RM, marine media ( $3.5 \%$ sea salt, $0.5 \%$ peptone, $0.1 \%$ yeast extract), at $25^{\circ} \mathrm{C}$ overnight, and $4 \mathrm{~mL}$ of the AltDE and AltDE1 inoculum were each transferred to $96 \mathrm{~mL}$ of $\mathrm{MB}$. The optical density (OD600) was measured using a spectrophotometer (BioSpectrometer ${ }^{\ominus}$; Eppendorf) and $150 \mu \mathrm{L}$ of 1.0 OD600 AltDE and AltDE1 were each used to inoculate $15 \mathrm{~mL}$ of media for each of 4 growth conditions. The first two conditions were designed to compare differences between different growth temperatures, therefore, AltDE and AltDE1 were grown in the marine medium at either 13 or $25^{\circ} \mathrm{C}$ until they reached mid-late exponential phase $(\mathrm{OD} 600=0.7-0.9)$. The second set of conditions was designed to examine differences between feasting and starving conditions, thus AltDE and AltDE1 were grown in minimal medium $(3.5 \%$ sea salt, $0.2 \%$ ammonium chloride, $0.05 \%$ potassium phosphate, $100 \mathrm{mM}$ Tris- $\mathrm{HCl}$ ) with or without $1 \%$ glucose at $25^{\circ} \mathrm{C}$. The "feasting" samples were subsequently collected at midlate exponential phase $(\mathrm{OD} 600=0.7-0.9)$. The "famine" samples were collected at the same time; however, they were centrifuged at $3000 \mathrm{rpm}$ for $5 \mathrm{~min}$, and the cells were washed with minimal medium and finally resuspended in $15 \mathrm{~mL}$ of minimal media without glucose. They were grown for 48 hours additional hours in minimal media without glucose and then collected for RNA extraction. Cultures for all conditions were performed in triplicate.

\section{RNA isolation}

The cultures were centrifuged at $7500 \mathrm{rpm}$ for $15 \mathrm{~min}$, resuspended in RNAlater ${ }^{\odot}$ Solution (Ambion \# AM7024, USA) and used directly for RNA extraction. Before total RNA extraction with the RNeasy ${ }^{\circ}$ Mini Kit (Qiagen \#74106) in accordance with the instruction from the manufacturer, cultures were incubated for $10 \mathrm{~min}$ at room temperature in $500 \mu \mathrm{l}$ of TE (Tris- $\mathrm{HCl} 10 \mathrm{mM}$, EDTA $1 \mathrm{mM}$, pH 8.0) with lysozyme $(2 \mathrm{mg} / \mathrm{ml})$ and proteinase $\mathrm{K}(0.4 \mathrm{mg} / \mathrm{ml})$. Genomic DNA was removed from the extracted RNA by treating the samples with DNAse I (Sigma-Aldrich \#AMPD1-1KT) at room temp for $30 \mathrm{~min}$. Agarose gel electrophoresis and staining confirmed the absence of genomic DNA in the RNA.

\section{cDNA synthesis}

Total RNA $(10 \mu \mathrm{g})$ was used to make single-stranded cDNA using High Capacity cDNA Reverse Transcription
(Applied Biosystems \#4368814) per the manufacturer's instructions. The second strand was synthesized by adding $30 \mathrm{U}$ of E. coli Polymerase I (New England Biolabs \#M0209L), 5U of E. coli DNA Ligase (New England Biolabs \#M0205S), $5 \mathrm{U}$ of RNase H (Epicentre \#R52250), $300 \mu \mathrm{M}$ of dNTPs (Invitrogen \#18427-013) to the first strand reaction. After $2,5 \mathrm{~h}$ at $16^{\circ} \mathrm{C}, 5 \mathrm{U}$ of T4 DNA polymerase (New England Biolabs \#M0203S) was added to the sample and maintaining at $16^{\circ} \mathrm{C}$ during $40 \mathrm{~min}$. Finally the double-stranded cDNA was cleaned with a QIAquick PCR Purification kit (Qiagen \#28104) and quantified using the ND-1000 Spectrophotometer (NanoDrop, Wilmington, USA). The quantity and quality of all cDNA samples were determined on an Agilent 2100 bioanalyzer.

\section{Sequencing and transcriptomic data analysis}

cDNA from the three biological replicates of each condition described above was pooled and used directly for sequencing using the Illumina HiSeq 2000 (100-bp paired-end read) sequencing platform (GATC Biotech). Sequence reads were pre-processed to remove lowquality bases, and reads shorter than $30 \mathrm{bp}$. Reads were first mapped using Bowtie software [50] against rDNA operon sequences of AltDE and AltDE1 strains. Remaining reads were subsequently mapped to the AltDE and AltDE1 chromosome sequence with the default parameters. SAMtools [51] were used to convert resulting data into BAM format. BamView [52] was subsequently used for the visualization of the sequence reads against the AltDE and AltDE1 genomes. Once the transcripts were mapped to the genomes, the expression values of genes were calculated as the number of reads aligned over each coding DNA sequence (CDS). Gene expression values were computed using RPKM normalization (reads per kilobase pair of transcript per million mapped reads). Genes exhibiting a $>2$ fold log change in RPKM between two conditions or strains were considered to have differential expression. To quantify high and low expression values, we used the average median value for all conditions within both strains as a cutoff. Cluster analysis and heat maps were prepared using the Multiexperiment Viewer (MeV) of the TM4 microarray software suite [32]. The transcriptome sequencing data has been submitted to NCBI SRA and is available with the accession numbers SRX447917 - SRX447925 (SRA Bioproject identifier PRJNA236321).

\section{Co-culture experiments}

AltDE and AltDE1 were both grown in marine media (as described above) to an OD600 1.0, at which point $5 \mu \mathrm{l}$ of AltDE and $5 \mu \mathrm{l}$ of AltDE1 were each added to $100 \mathrm{~mL}$ of the appropriate media in three separate, sterile flasks, providing triplicate biological replication. In addition, $10 \mu \mathrm{l}$ of AltDE and $10 \mu \mathrm{l}$ of AltDE1 were added to sterile 
flasks containing the same media $(100 \mathrm{~mL})$ separately to act as controls for each experiment. Co-cultures were performed using each of the four growth conditions described above. Subsamples $(2 \mathrm{~mL})$ were taken from the co-cultures and controls after 1,7 and 14 days of growth. At each time point, DNA was extracted from the resulting cell pellet using QIAprep Spin Miniprep kits (Qiagen 27106) for PCR analysis (described below) and CFUs were counted for the day 7 samples (described below).

\section{PCR amplification of the strain specific o-chain region}

PCR amplification was performed for each DNA sample described above using primers designed to target the O-chain gene cluster of AltDE and AltDE1. This region of the genome has been shown to be quite distinct between the two strains [3], and we were able to design the following primers that target only AltDE or AltDE1: AltDE-ochain-for 5'GATGCCGCCCATTTT GATCC3'; AltDE-ochain-rev 5'AGGTTGGAGACCAA AGCTCG3'; AltDE1-ochain-for 5'AACGATGAAGG GAGCTCGTG3'; and AltDE1-ochain-rev 5'TAGCGC AGTGGCTGAAAGAA3'. All PCR reactions were performed using BIOTAQ DNA polymerase (BioLine BIO$21040)$ in $50 \mu \mathrm{L}$ reactions as follows: $37.5 \mu \mathrm{L}$ sterile water, $5 \mu \mathrm{L} 10 \times$ reaction buffer, $4 \mu \mathrm{L}$ of $\mathrm{MgCl} 2(25 \mathrm{mg} / \mathrm{mL}), 1 \mu \mathrm{L}$ of a dNTP mix $(10 \mathrm{mM}), 1 \mu \mathrm{L}$ each primer $(10 \mu \mathrm{M})$ and $0.5 \mu \mathrm{L}$ BIOTAQ polymerase $(5 \mathrm{U} / \mu \mathrm{l})$. A PTC-100 Peltier Thermal Cycler (MJ Research Inc.) was used with the following temperature cycling profile: 1 cycle at $95^{\circ} \mathrm{C}$ for $5 \mathrm{~min} ; 23$ cycles at $94^{\circ} \mathrm{C}$ for $45 \mathrm{~s}, 57^{\circ} \mathrm{C}$ for $45 \mathrm{~s}$ and $72^{\circ} \mathrm{C}$ for $1 \mathrm{~min}$; and 1 cycle at $72^{\circ} \mathrm{C}$ for $10 \mathrm{~min}$. The cycle number was optimized using AltDE/AltDE1 DNA in known quantities. All PCR amplification products were visualized using electrophoresis on $0.8 \%$ agarose gels with a $1 \mathrm{~Kb}$ ladder as a size reference.

\section{Colony Forming Units (CFUs)}

In a prior work, we showed that AltDE is susceptible to the antibiotic phleomycin (Invivogen), while AltDE1 is not [23]. We used that distinction to design an assay, which enumerates the CFUs for each strain during co-culture of AltDE and AltDE1 when grown in either RM or MMG. After 7 days of co-culture an aliquot was taken and serial dilutions plated on both marine agar, in which both strains grow, and marine agar with phleomycin (100 ug). The CFUs from the latter plates (representing the number of AltDE1 cells) were then subtracted from the CFUs for the marine agar plates (representing total bacteria cells), providing an estimate of AltDE cells as well. Each experiment included AltDE and AltDE1 pure culture as controls, while the co-cultures were done in triplicate for biological replicates.

\section{Motility assay}

AltDE and AltDE1 were inoculated (0.1\%) into $50 \mathrm{ml}$ of each of the following: $\mathrm{RM} 13^{\circ} \mathrm{C}, \mathrm{RM} 25^{\circ} \mathrm{C}$, and $\mathrm{MMG}$ $25^{\circ} \mathrm{C}$. They were grown to an OD600 1.0 , and $1 \mu \mathrm{L}$ of each culture was stabbed into the center of a $0.25 \%$ RM or MMG agar plates. The plates were then incubated at the appropriate temperature for $48 \mathrm{~h}$, and the diameter of the growth zone was measured at 24 and 48 h. Each experiment was performed in triplicate for both strains, and statistical analyses were performed on the combined data from 24 and 48 hours using the three data sets for each condition. We used a two-tailed student's $t$-test to determine whether there was significant $(\mathrm{p}<0.05)$ variation between AltDE and AltDE1 motility.

\section{Additional files}

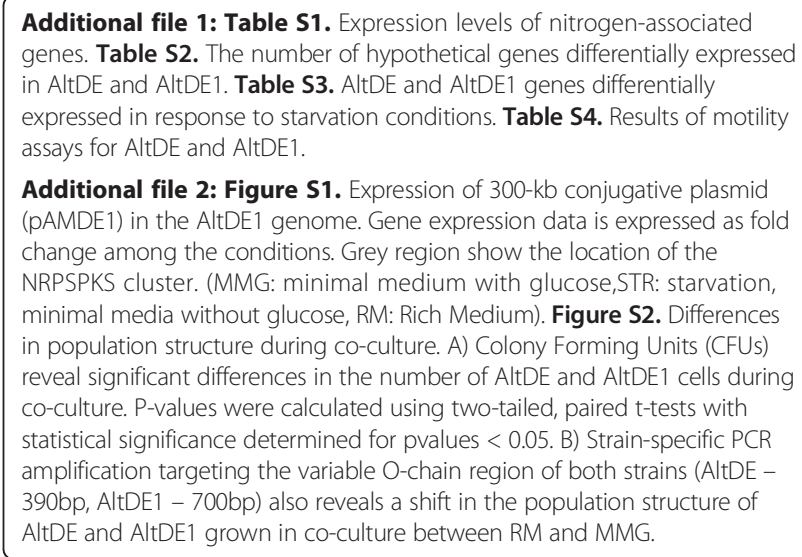

Competing interests

The authors declared that they have no competing interests.

\section{Authors' contributions}

FRV conceived this study. NEK and EA carried out the growth cultures and performed RNA extractions, while MLP was responsible for making the CDNA. NEK, MLP and RG performed the transcriptomic data analysis. NEK performed the co-culture and motility experiments. FRV participated in the design and oversight of this project. NEK, MLP, RG and FRV participated in the drafting of this manuscript. All authors read and approved the final manuscript.

\section{Acknowledgments}

This work was supported by projects MICROGEN (Programa CONSOLIDERINGENIO 2010 CSD2009-00006) from the Spanish Ministerio de Ciencia e Innovación, MEDIMAX BFPU2013-48007-P from the Spanish Ministerio de Economía y Competitividad, MaCuMBA Project 311975 of the European Commission FP7, ACOMP/2014/024, AORG 2014/032 and PROMETEO II/2014/ 012 from the Generalitat Valenciana.. R.G. was supported by a Juan de la Cierva scholarship from the Spanish Ministerio de Ciencia e Innovación.

Received: 29 January 2014 Accepted: 16 October 2014

Published: 26 October 2014

\section{References}

1. López-Pérez M, Gonzaga A, Rodriguez-Valera F: Genomic diversity of "deep ecotype" Alteromonas macleodii isolates. Evidence for panMediterranean clonal frames. Genome Biol Evol 2013, 5:1220-1232.

2. López-Pérez M, Gonzaga A, Martin-Cuadrado A, Onyshchenko O, Ghavidel A, Ghai R, Rodriguez-Valera F: Genomes of surface isolates of Alteromonas 
macleodii: the life of a widespread marine opportunistic copiotroph. Sci Rep 2012, 2:696. doi:10.1038/srep00696.

3. Gonzaga A, Martin-Cuadrado AB, López-Pérez M, Mizuno CM, García-Heredia I, Kimes NE, Lopez-García P, Moreira D, Ussery D, Zaballos M, Ghai R, Rodriguez-Valera F: Polyclonality of concurrent natural populations of Alteromonas macleodii. Genome Biol Evol 2012, 4:1360-1374.

4. García-Martínez J, Acinas SG, Massana R, Rodríguez-Valera F: Prevalence and microdiversity of Alteromonas macleodii-like microorganisms in different oceanic regions. Environ Microbiol 2002, 4:42-50.

5. McCarren J, Becker JW, Repeta DJ, Shi Y, Young CR, Malmstrom RR, Chisholm SW, DeLong EF: Microbial community transcriptomes reveal microbes and metabolic pathways associated with dissolved organic matter turnover in the sea. Proc Natl Acad Sci U S A 2010, 107:16420-16427.

6. Baker BJ, Sheik CS, Taylor CA, Jain S, Bhasi A, Cavalcoli JD, Dick GJ: Community transcriptomic assembly reveals microbes that contribute to deep-sea carbon and nitrogen cycling. ISME J 2013, 7:1962-1973. doi:10.1038/ismej.2013.85

7. Acinas SG, Anton J, Rodriguez-Valera F: Diversity of free-living and attached bacteria in offshore western Mediterranean waters as depicted by analysis of genes encoding 16S rRNA. Appl Environ Microbiol 1999, 65:514-522.

8. Pedler BE, Aluwihare LI, Azam F: Single bacterial strain capable of significant contribution to carbon cycling in the surface ocean. Proc Natl Acad Sci U S A 2014, 111:7202-7207.

9. Ivars-Martinez E, Martin-Cuadrado A-B, D'Auria G, Mira A, Ferriera S, Johnson J, Friedman R, Rodriguez-Valera F: Comparative genomics of two ecotypes of the marine planktonic copiotroph Alteromonas macleodii suggests alternative lifestyles associated with different kinds of particulate organic matter. ISME J 2008, 2:1194-1212.

10. Tettelin H, Riley D, Cattuto C, Medini D: Comparative genomics: the bacterial pan-genome. Curr Opin Microbiol 2008, 11:472-477.

11. Medini D, Donati C, Tettelin H, Masignani V, Rappuoli R: The microbial pangenome. Curr Opin Genet Dev 2005, 15:589-594.

12. Tettelin H, Masignani V, Cieslewicz MJ, Donati C, Medini D, Ward NL, Angiuoli SV, Crabtree J, Jones AL, Durkin AS: Genome analysis of multiple pathogenic isolates of Streptococcus agalactiae: implications for the microbial "pan-genome". Proc Natl Acad Sci U S A 2005, 102:13950-13955.

13. Chun J, Grim CJ, Hasan NA, Lee JH, Choi SY, Haley BJ, Taviani E, Jeon Y, Kim DW, Lee J, Brettin TS, Bruce DC, Challacombe JF, Detter JC, Han CS, Munk AC, Chertkov O, Meincke L, Saunders E, Walters RA, Huq A, Nair GB, Colwell RR: Comparative genomics reveals mechanism for short-term and longterm clonal transitions in pandemic Vibrio cholerae. Proc Natl Acad Sci U S A 2009, 106:15442-15447.

14. Conlan S, Mijares LA, Becker J, Blakesley RW, Bouffard GG, Brooks S, Coleman H, Gupta J, Gurson N, Park M: Staphylococcus epidermidis pan-genome sequence analysis reveals diversity of skin commensal and hospital infection-associated isolates. Genome Biol 2012, 13:R64.

15. Lukjancenko O, Wassenaar TM, Ussery DW: Comparison of 61 sequenced Escherichia coli genomes. Microb Ecol 2010, 60:708-720.

16. Mira A, Martin-Cuadrado AB, D'Auria G, Rodriguez-Valera F: The bacterial pan-genome:a new paradigm in microbiology. Int Microbiol 2010, 13:45-57.

17. Pinto A, Melo-Barbosa H, Miyoshi A, Silva A, Azevedo V: Application of RNA-seq to reveal the transcript profile in bacteria. Genet Mol Res 2011, 10:1707-1718

18. Haas BJ, Chin M, Nusbaum C, Birren BW, Livny J: How deep is deep enough for RNA-Seq profiling of bacterial transcriptomes? BMC Genomics 2012, 13:734.

19. Deutscher MP: Chapter 9 Maturation and Degradation of Ribosomal RNA in Bacteria. In Progress in Molecular Biology and Translational Science, Volume 85. Edited by Ciaran C. San Diego: Academic Press, Elsevier; 2009:369-391.

20. Lopez-Perez M, Gonzaga A, Ivanova E, Rodriguez-Valera F: Genomes of Alteromonas australica, a world apart. BMC Genomics 2014, 15:483.

21. Mazel D: Integrons: agents of bacterial evolution. Nat Rev Micro 2006, 4:608-620.

22. Coutts $G$, Thomas $G$, Blakey D, Merrick M: Membrane sequestration of the signal transduction protein $\mathrm{GlnK}$ by the ammonium transporter AmtB. EMBO J 2002, 21:536-545.

23. Mizuno CM, Kimes NE, López-Pérez M, Ausó E, Rodriguez-Valera F, Ghai R: A Hybrid NRPS-PKS Gene Cluster Related to the Bleomycin Family of
Antitumor Antibiotics in Alteromonas macleodii Strains. Plos One 2013 8:e76021.

24. Scaria J, Mao C, Chen J-W, McDonough SP, Sobral B, Chang Y-F: Differential Stress Transcriptome Landscape of Historic and Recently Emerged Hypervirulent Strains of Clostridium difficile Strains Determined Using RNA-seq. Plos One 2013, 8:e78489.

25. Prágai Z, Harwood CR: Regulatory interactions between the Pho and $\sigma B$ dependent general stress regulons of Bacillus subtilis. Microbiology 2002 148:1593-1602.

26. El-Sharoud WM, Niven GW: The influence of ribosome modulation factor on the survival of stationary-phase Escherichia coli during acid stress. Microbiology 2007, 153:247-253.

27. Niven GW: Ribosome modulation factor protects Escherichia coli during heat stress, but this may not be dependent on ribosome dimerisation. Arch Microbiol 2004, 182:60-66

28. Janosi L, Mottagui-Tabar S, Isaksson LA, Sekine Y, Ohtsubo E, Zhang S, Goon S, Nelken S, Shuda M, Kaji A: Evidence for in vivo ribosome recycling, the fourth step in protein biosynthesis. EMBO J 1998, 17:1141-1151.

29. Garcia-Heredia I, Martin-Cuadrado A-B, Mojica FJM, Santos F, Mira A, Antón J, Rodriguez-Valera F: Reconstructing Viral Genomes from the Environment Using Fosmid Clones: The Case of Haloviruses. Plos One 2012, 7:e33802.

30. Brüssow H, Canchaya C, Hardt W-D: Phages and the evolution of bacterial pathogens: from genomic rearrangements to lysogenic conversion. Microbiol Mol Biol Rev 2004, 68:560-602.

31. Smoot LM, Smoot JC, Graham MR, Somerville GA, Sturdevant DE, Migliaccio CAL, Sylva GL, Musser JM: Global differential gene expression in response to growth temperature alteration in group A Streptococcus. Proc Natl Acad Sci U S A 2001, 98:10416-10421.

32. Saeed Al, Bhagabati NK, Braisted JC, Liang W, Sharov V, Howe EA, Li J, Thiagarajan M, White JA, Quackenbush J: [9] TM4 Microarray Software Suite. Methods Enzymol 2006, 411:134-193.

33. Zegans ME, Wagner JC, Cady KC, Murphy DM, Hammond JH, OToole GA Interaction between bacteriophage DMS3 and host CRISPR region inhibits group behaviors of Pseudomonas aeruginosa. J Bacterio/ 2009, 191:210-219.

34. Westra ER, Buckling A, Fineran PC: CRISPR-Cas systems: beyond adaptive immunity. Nat Rev Microbiol 2014, 12:317-326.

35. Repoila F, Darfeuille F: Small regulatory non-coding RNAs in bacteria: physiology and mechanistic aspects. Biol Cell 2009, 101:117-131.

36. Lessa FA, Raiol T, Brigido MM, Martins Neto DS, Walter MEM, Stadler PF: Clustering Rfam 10.1: Clans, families, and classes. Genes 2012, 3:378-390.

37. Li L, Huang D, Cheung MK, Nong W, Huang Q, Kwan HS: BSRD: a repository for bacterial small regulatory RNA. Nucleic Acids Res 2013, 41:D233-D238.

38. Ellis JC, Brown JW: The RNase P family. RNA Biol 2009, 6:362-369.

39. Lai LB, Vioque A, Kirsebom LA, Gopalan V: Unexpected diversity of RNase $P$, an ancient tRNA processing enzyme: challenges and prospects. FEBS Lett 2010, 584:287-296.

40. Muto A, Fujihara A, Ito K, Matsuno J, Ushida C, Himeno H: Requirement of transfer-messenger RNA for the growth of Bacillus subtilis under stresses. Genes Cells 2000, 5:627-635.

41. Shin J-H, Price CW: The SsrA-SmpB ribosome rescue system is important for growth of Bacillus subtilis at low and high temperatures. J Bacteriol 2007, 189:3729-3737

42. Abe T, Sakaki K, Fujihara A, Ujiie H, Ushida C, Himeno H, Sato T, Muto A: tmRNA-dependent trans-translation is required for sporulation in Bacillus subtilis. Mol Microbiol 2008, 69:1491-1498.

43. Okan NA, Bliska JB, Karzai AW: A role for the SmpB-SsrA system in Yersinia pseudotuberculosis pathogenesis. PLoS Pathol 2006, 2:e6.

44. Himeno $\mathrm{H}$, Kurita D, Muto A: tmRNA-mediated trans-translation as the major ribosome rescue system in a bacterial cell. Front Genet 2014, 5:66.

45. Nudler E, Mironov AS: The riboswitch control of bacterial metabolism. Trends Biochem Sci 2004, 29:11-17.

46. Winkler W, Nahvi A, Breaker RR: Thiamine derivatives bind messenger RNAs directly to regulate bacterial gene expression. Nature 2002, 419:952-956.

47. Lambowitz AM, Zimmerly S: Group II introns: mobile ribozymes that invade DNA. Cold Spring Harb Perspect Biol 2011, 3:a003616.

48. López-Pérez M, Gonzaga A, Martin-Cuadrado A-B, López-García P Rodriguez-Valera F, Kimes N: Intra- and Intergenomic Variation of Ribosomal RNA Operons in Concurrent Alteromonas macleodii Strains. Microb Ecol 2013, 65:720-730. 
49. Rodriguez-Valera F, Martin-Cuadrado A-B, Rodriguez-Brito B, Pasic L, Thingstad TF, Rohwer F, Mira A: Explaining microbial population genomics through phage predation. Nat Rev Micro 2009, 7:828-836.

50. Langmead B, Trapnell C, Pop M, Salzberg SL: Ultrafast and memoryefficient alignment of short DNA sequences to the human genome. Genome Biol 2009, 10:R25.

51. Li H, Handsaker B, Wysoker A, Fennell T, Ruan J, Homer N, Marth G, Abecasis G, Durbin R: The sequence alignment/map format and SAMtools. Bioinformatics 2009, 25:2078-2079.

52. Carver T, Harris SR, Otto TD, Berriman M, Parkhill J, McQuillan JA: BamView: visualizing and interpretation of next-generation sequencing read alignments. Brief Bioinform 2012, 14:203-212.

doi:10.1186/1471-2164-15-938

Cite this article as: Kimes et al:: RNA sequencing provides evidence for functional variability between naturally co-existing Alteromonas macleodii lineages. BMC Genomics 2014 15:938.

\section{Submit your next manuscript to BioMed Central and take full advantage of:}

- Convenient online submission

- Thorough peer review

- No space constraints or color figure charges

- Immediate publication on acceptance

- Inclusion in PubMed, CAS, Scopus and Google Scholar

- Research which is freely available for redistribution 